\title{
Fostamatinib Disodium Anhydrous
}

National Cancer Institute

\section{Source}

National Cancer Institute. Fostamatinib Disodium Anhydrous. NCI Thesaurus. Code C95228.

The anhydrous form of fostamatinib disodium, an orally available Syk kinase inhibitor with potential anti-inflammatory and immunomodulating activities. Fostamatinib inhibits Syk kinase-mediated Ig G Fc gamma receptor signaling, resulting in inhibition of the activation of mast cells, macrophages, and B-cells and related inflammatory responses and tissue damage. Syk kinase, widely expressed in hematopoietic cells, is a nonreceptor tyrosine kinase that is involved in coupling activated immunoreceptors to signal downstream events that mediate diverse cellular responses, including proliferation, differentiation, and phagocytosis. 